\title{
MANAJEMEN NYERI PASIEN RAWAT JALAN PADA KASUS HERNIA NUKLEUS PULPOSUS MELALUI CORE STABILITY
}

\author{
Elsa Roselina ${ }^{1}$, Safrin Arifin², Hermito Gidion ${ }^{3}$ \\ ${ }^{\prime}$ Tenaga Pengajar Program Studi Perumahsakitan Universitas Indonesia \\ ${ }^{2}$ Tenaga Pengajar Program Studi Fisioterapi Universitas Indonesia \\ ${ }^{s}$ Tenaga Pengajar Program Studi Okupasi Terapi Universitas Indonesia
}

\begin{abstract}
Abstrak - Hernia Nukleus Pulposus (HNP) merupakan suatu keadaan dimana annulus fibrosus beserta nukleus pulposusnya menonjol ke dalam kanalis spinalis. Penderita HNP sering mengeluh sakit punggung menjalar ke tungkai bawah terutama saat aktivitas membungkuk. Program rehabilitasi dilakukan untuk membantu mengurangi nyeri. Penelitian ini bertujuan untuk diketahuinya treatment yang lebih efektif antara William's Flexion dibandingkan Core Stability dalam menurunkan rasa nyeri pada pasien dengan kasus HNP. Penelitian ini menggunakan desain eksperimental double blind dengan nilai alpha 5\%. Penelitian dilakukan di Klinik "X". Sampel penelitian berjumlah 18 orang pasien dengan diagnosa medis HNP yang menjalani program terapi dari bulan September sampai dengan Desember 2013, diambil dengan tehnik randomisasi. Nyeri diukur dengan menggunakan Visual Analoque Scale (VAS). Hasil analisis dengan uji t menunjukkan bahwa Core stability (mean $=4,56, \mathrm{SD}=1,130$ ) lebih efektif dibandingkan dengan William's flexion [mean $=2,78, \mathrm{SD}=0,972 ; \mathrm{t}(16)=-3,578, \mathrm{p}=0,003]$ dalam menurunkan nyeri pasien HNP. Hasil penelitian dengan One-Way ANOVA menunjukkan bahwa tidak ada perbedaan secara signifikan dalam penurunan nyeri yang dihasilkan oleh frekuensi treatment William's flexion $[\mathrm{F}(2,6)=1,857$, $\mathrm{p}=0,236]$. Sebaliknya, terdapat perbedaan secara signifikan dalam penurunan nyeri yang dihasilkan oleh frekuensi treatment Core stability $[\mathrm{F}(1,6)=12,333, \mathrm{p}=0,007]$.
\end{abstract}

Kata Kunci: Core stability, Hernia Nukleus Pulposus

Abstract - Herniated nucleus pulposus (HNP) is a situation where the annulus fibrosus along nucleus pulposus protruding into the spinal canal. HNP patients often complain of back pain radiating to the lower limbs, especially when bending activity. Rehabilitation programs do to help reduce the pain. The aim of this research knew which treatment was more effective among William's Flexion compared to Core Stability in reducing pain for HNP patients. This study used a double-blind experimental design with an alpha value of 5\%. The study was conducted at the Clinic "X". Sample was 18 patients with medical diagnoses HNP undergoing therapy from September to December 2013, taken with randomization techniques. Pain was measured using the Visual Analoque Scale (VAS). The results of the t-test analysis showed that Core stability (mean $=4.56, S D=1.130$ ) was more effective than William's flexion [mean $=2.78, S D=0.972 ; t(16)=-$ 3.578, $p=0.003]$ in reducing pain for HNP patients. The results of One-Way ANOVA showed that there was no significant difference in pain reduction produced by William's flexion frequency of treatment $[F(2$, $6)=1.857, p=0.236]$. In contrast, there were significant differences in pain reduction produced by Core stability frequency treatment $[F(1,6)=12.333, p=0.007]$.

Keywords: Core stability, Herniated Nucleus Pulposus 


\section{PENDAHULUAN}

\section{Latar Belakang}

Nyerimerupakan masalahkesehatan masyarakat yang secara umum akan berpengaruh besar pada kehidupanpasiendan keluarga mereka (Weiss, 1999). Baik nyeri kronis maupun akut, merupakan halumum danmemilikidampak kesehatanyang signifikan (Strassels, Chen, Carr, 2002). Nyeri punggung bawah (NPB) adalah nyeri yang dirasakan di daerah punggung bawah, dapat berupa nyeri lokal ataupun disertai nyeri radikuler atau keduanya yang disebabkan oleh iritasi atau kompresi radiks pada satu atau beberapa radiks lumbosakral yang dapat disertai dengan kelemahan motorik, gangguan sensorik dan menurunnya refleks fisiologik (Meliala, Suryamiharja, Purba, Anggraini, 2000). Masalah NPB menjadi penting karena diperkirakan $80 \%$ penduduk selama hidup pernah merasakan nyeri punggung bawah. Setiap saat lebih dari $10 \%$ penduduk menderita NPB. Insidens di beberapa negara berkembang lebih kurang 15-20\% dari total populasi. Diperkirakan 15\% dari jumlah penduduk menderita NPB (Lubis I, 2003).

Sekitar $40 \%$ nyeri punggung bawah disebabkan oleh Hernia Nukleus Pulposus (HNP), dimana penderita sering mengeluh sakit punggung menjalar ke tungkai bawah terutama saat aktivitas membungkuk (Olmakers, 1998). HNP mempunyai karakteristik berupa protusi dari annulus fibrosus beserta nucleus pulposus yang ada di dalamnya ke dalam canalis vertebralis (Gilroy J, 2000).
Pelbagai macam terapi dilakukan untuk meringankan keluhan nyeri pada pasien HNP, diantaranya dengan treatmentWilliam's flexion dan Core Stability. Hasil penelitian yang dilakukan oleh Khalid, Rafiq, Zehra (2013) membuktikan bahwa intensitas nyeri pasien berkurang secara signifikan setelah mengikuti lima sesi latihan William's Flexion. Wang, et. al (2012) pun memperlihatkan hasil penelitiannya dengan meta analisis bahwa dibandingkan dengan latihan umum (general exercise), latihan Core Stability lebih efektif dalam menurunkan nyeri pada pasein dengan NPB kronik dalam waktu yang singkat.

Namun, penelitian yang membandingkan efektivitas diantara kedua treatment tersebut di Indonesia belum ditemukan. Untuk itu penelitian ini diadakan. Dengan harapan akan memberikan manfaat bagi pasien yang menjalani pengobatan rawat jalan untuk mendapatkan terapi yang lebih baik dalam meringankan rasa nyeri HNP yang diderita.

\section{Pokok Masalah}

Insiden Nyeri Punggung Bawah, dimana $40 \%$ disebabkan oleh HNP cukup besar. William's Flexion maupun Core Stability merupakan treatment yang dapat menurunkan nyeri pada pasien HNP. Namun, penelitian yang membandingkan efektivitas William's Flexion dibandingkan Core Stability belum pernah dilakukan di Klinik "X".

\section{Tujuan Penelitian}

Penelitian ini bertujuan untuk diketahuinya treatment yang lebih efektif 
antara William's Flexion dibandingkan Core Stability dalam menurunkan rasa nyeri pasien pada kasus HNP (Hernia Nukleus Pulposus).

\section{Metode Penelitian}

Penelitian ini menggunakan pendekatan kuantitatif dengan desain penelitian eksperimental double blind. Penelitian dilakukan di Klinik "X”. Populasi penelitian adalah pasien dengan diagnosa medis HNP yang menjalani pengobatan rawat jalan. Sampel pada penelitian ini adalah pasien dengan diagnosa medis HNP yang menjalani program terapi dari bulan September sampai dengan Desember 2013. Sampel diambil dengan menggunakan tehnik randomisasi. Penelitian ini menggunakan sumber data primer dengan kuesioner sebagai instrumennya. Nyeri diukur dengan menggunakan Visual Analoque Scale (VAS). Setelah data terkumpul, data dimasukan ke dalam perangkat lunak statistik dan dianalisa dengan uji t dan ANOVA, dengan nilai alpha $5 \%$.

\section{ANALISIS DAN PEMBAHASAN}

Pada kelompokCore stability, rata-rata usia responden adalah 45,78 tahun, dengan usia termuda responden 24 tahun dan usia tertua 60 tahun. Pada kelompok William's Flexion, rata-rata usia responden adalah 55,22 tahun, dengan usia termuda responden 47 tahun dan usia tertua 62 tahun. Hal ini dapat dilihat pada tabel 1 .

Mayoritas responden pada kelompok Core stability berjenis kelamin laki-laki, yaitu 6 orang (66,7\%), sedangkan pada kelompok William's Flexion mayoritas responden berjenis kelamin perempuan, yaitu 7 orang $(77,8 \%)$.

Mayoritas responden pada kelompok Core stability menjalani terapi 1 kali, yaitu sebanyak 6 orang (66,7\%). Pada kelompok William's Flexion responden menjalani terapi 1, 2 dan 3 hingga 5 kali, yaitu masing-masing sebanyak 3 orang (33,3\%).

Hal ini secara lengkap terdapat pada tabel 2.

Pada kelompok Core stability, rata-rata skala nyeri sebelum tindakan adalah 6,22 dan rata-rata skala nyeri sesudah tindakan adalah 1,67. Rata-rata penurunan skala nyeri responden adalah 4,56. Pada kelompok William's Flexion, rata-rata skala nyeri sebelum tindakan adalah 4,56 dan rata-rata skala nyeri sesudah tindakan adalah 1,78. Rata-rata penurunan skala nyeri responden adalah 2,78. Hal ini dapat dilihat pada tabel 3.

Selanjutnya dilakukan uji normalitas data pada variabel penurunan skala nyeri, dimana nilai Shapiro-Wilk menunjukkan hasil data berdistribusi normal (nilai $\mathrm{p}<0,068$ ).

Hasil analisis dengan uji t menunjukkan bahwa Core stability (mean $=4,56$, $S D=1,130)$ lebih efektif dibandingkan dengan William's flexion $[$ mean $=2,78, \quad S D=0,972$; $t(16)=-3,578, \quad p=0,003]$ dalam menurunkan nyeri pasien HNP. Hasil analisis dengan OneWay ANOVA memperlihatkan bahwa tidak ada perbedaan secara signifikan dalam penurunan nyeri yang dihasilkan oleh frekuensi treatment William's flexion $[F(2$, $6)=1,857, \quad p=0,236]$. Sebaliknya, terdapat perbedaan secara signifikan dalam penurunan 
nyeri yang dihasilkan oleh frekuensi treatment

Core stability $[F(1,6)=12,333, p=0,007]$. Hasil analisisnya dapat dilihat pada tabel 4 dan 5 , serta gambar 1 dan 2.

Tabel 1

Distribusi Responden Menurut Usia

\begin{tabular}{lccccc}
\hline Kelompok & Mean & Median & SD & Min - Mak & $95 \%$ CI \\
\hline Core stability & 45,78 & 48 & 5,17 & $24-60$ & $37,37-54,19$ \\
William'sflexion & 55,22 & 56 & 10,94 & $47-62$ & $51,25-59,19$ \\
\hline
\end{tabular}

Tabel 2

Distribusi Responden Menurut Jenis Kelamin dan Frekuensi Terapi

\begin{tabular}{|c|c|c|c|c|c|}
\hline \multirow{2}{*}{ Karakteristik } & \multirow{2}{*}{ Kategori } & \multicolumn{2}{|c|}{ Kelompok Core stability } & \multicolumn{2}{|c|}{$\begin{array}{l}\text { Kelompok William's } \\
\text { flexion }\end{array}$} \\
\hline & & Jumlah & Persentase (\%) & Jumlah & $\begin{array}{c}\text { Persentase } \\
(\%)\end{array}$ \\
\hline \multirow[t]{2}{*}{ Jenis kelamin } & Perempuan & 3 & 33,3 & 7 & 77,8 \\
\hline & Laki-laki & 6 & 66,7 & 2 & 22,2 \\
\hline \multirow[t]{3}{*}{ Frekuensi terapi } & Sekali & 3 & 33,3 & 6 & 66,7 \\
\hline & Dua kali & 3 & 33,3 & 2 & 22,2 \\
\hline & $\begin{array}{l}\text { Tiga hingga lima } \\
\text { kali }\end{array}$ & 3 & 33,3 & 1 & 11,2 \\
\hline
\end{tabular}

Tabel 3

Distribusi Responden Menurut Nilai Skala Nyeri

\begin{tabular}{|c|c|c|c|c|c|c|}
\hline Karakteristik & Kategori & Mean & Median & SD & $\begin{array}{l}\text { Min - } \\
\text { Mak }\end{array}$ & $95 \% \mathrm{CI}$ \\
\hline Skala nyeri & Sebelum terapi & 6,22 & 6 & 1,20 & $4-8$ & $5,30-7,15$ \\
\hline $\begin{array}{l}\text { kelompok Core } \\
\text { stability }\end{array}$ & Sesudah terapi & 1,67 & 2 & 0,70 & $1-3$ & $1,12-2,21$ \\
\hline Skala nyeri & Sebelum terapi & 4,56 & 4 & 1,01 & $4-7$ & $3,78-5,33$ \\
\hline $\begin{array}{l}\text { kelompok } \\
\text { William's flexion }\end{array}$ & Sesudah terapi & 1,78 & 2 & 0,83 & $1-3$ & $1,14-2,42$ \\
\hline \multirow{2}{*}{$\begin{array}{l}\text { Penurunan } \\
\text { nyeri }\end{array}$} & Kelompok Core stability & 4,56 & 4 & 1,13 & $3-7$ & $3,69-5,42$ \\
\hline & $\begin{array}{l}\text { Kelompok William's } \\
\text { flexion }\end{array}$ & 2,78 & 3 & 0,97 & $2-5$ & $2,03-3,52$ \\
\hline
\end{tabular}

Tabel 4

Hasil Analisa Data dengan Uji T

\begin{tabular}{llccccc}
\hline Karakteristik & Kategori & Mean & SD & t & df & Nilai p \\
\hline Penurunan & Kelompok Core stability & 4,56 & 1,13 & \multirow{2}{*}{$-3,578$} & \multirow{2}{*}{16} & \multirow{2}{*}{0,003} \\
nyeri & Kelompok William's flexion & 2,78 & 0,97 & & & \\
\hline
\end{tabular}

Tabel 5

Hasil analisa data dengan One-Way ANOVA 


\begin{tabular}{|c|c|c|c|c|c|c|c|}
\hline Karakteristik & Frekuensi terapi & $\mathrm{N}$ & Mean & $\mathrm{df} 1$ & $\mathrm{df} 2$ & $\mathrm{~F}$ & Nilai p \\
\hline Kelompok & Sekali & 3 & 2,00 & & & & \\
\hline \multirow[t]{2}{*}{ William's flexion } & Dua kali & 3 & 3,00 & 2 & 6 & 1,857 & 0,236 \\
\hline & Tiga hingga lima kali & 3 & 3,33 & & & & \\
\hline \multirow{3}{*}{$\begin{array}{l}\text { Kelompok Core } \\
\text { stability }\end{array}$} & Sekali & 6 & 4,00 & & & & \\
\hline & Dua kali & 2 & 5,00 & 1 & 6 & 12,333 & 0,007 \\
\hline & Tiga hingga lima kali & 1 & 7,00 & & & & \\
\hline
\end{tabular}

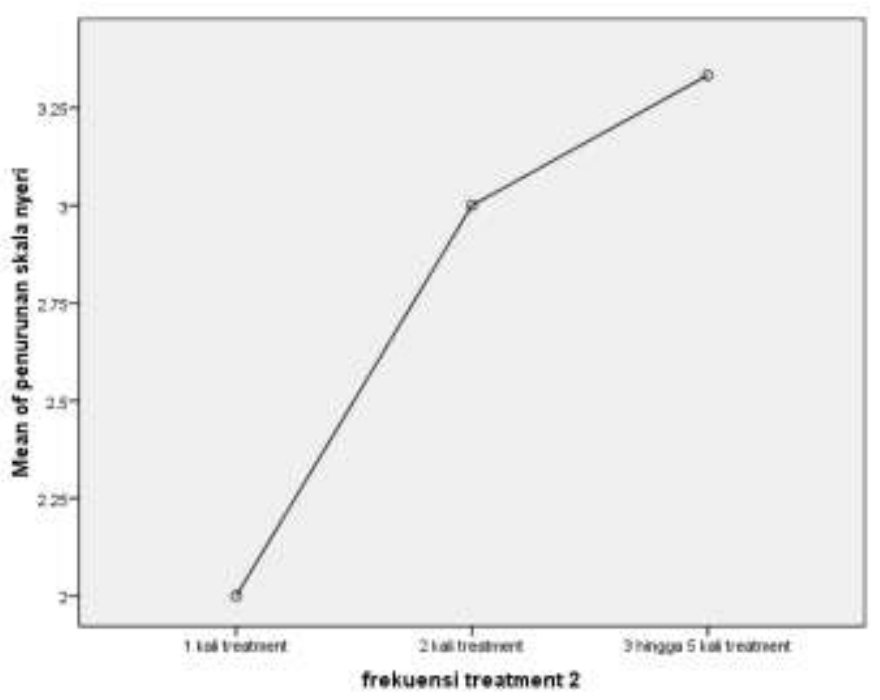

Gambar 1. Nilai mean penurunan skala nyeri berdasarkan frekuensi terapi pada kelompok William's flexion

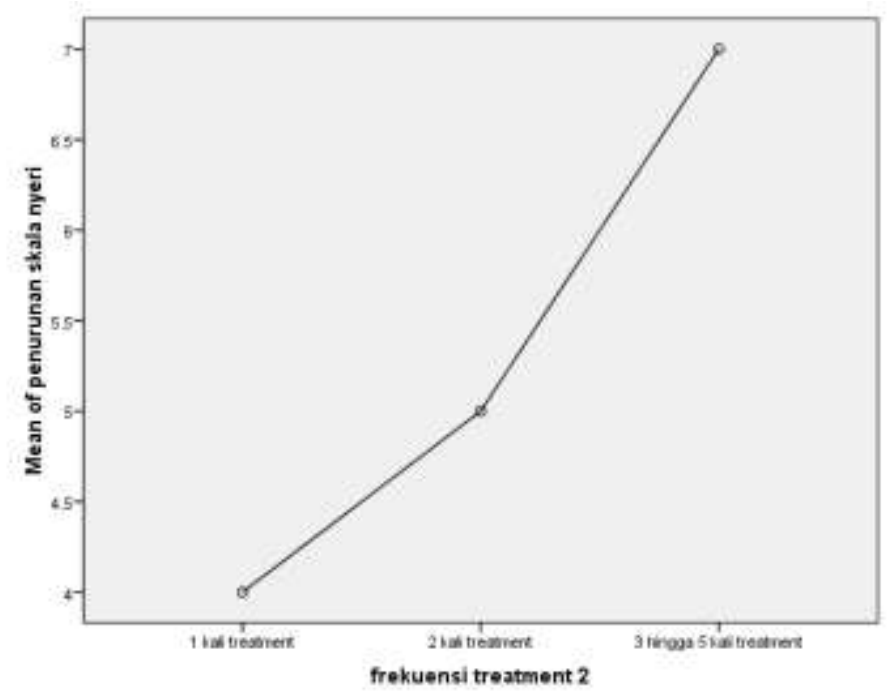

Gambar 2. Nilai mean penurunan skala nyeri berdasarkan frekuensi terapi pada kelompok Core stability 
Latihan William's flexion merupakan seperangkat latihan fisik yang digunakan untuk meningkatkan fleksi lumbal, menghindari ekstensi lumbal dan memperkuat otot-otot perut serta gluteus untuk mengelola NPB (Matsudaira, Hara, Arisaka, Isomura, 2011). Scheermesser et.al (2012) dalam penelitiannya menemukan bahwa terapi fisik dapat memperbaiki fungsi dan kemampuan pasien. Demikian pula halnya dengan hasil penelitian Khalid, Rafiq, Zehra (2013) yang membuktikan bahwa latihan William's flexion memperbaiki kondisi NPB. William's flexion akan mengurangi tekanan posterior dari bagian lumbal dan spinal, dimana latihan ini akan mengembalikan gerakan dan kekuatan punggung bawah yang membantu dalam mengurangi nyeri dan mencegah kekambuhan NPB (American academy of orthopedic surgeon, 2009). Latihan William's flexion juga memperkuat otot-otot punggung dan abdomen yang mempertahankan semua struktur dan mencegah kelebihan beban bagian lumbal dan spinal.

Core stability telah menjadi tren modalitas untuk menangani kasus nyeri pinggang bawah, mengikuti prinsip-prinsip penguatan otot-otot core (otot-otot core yang meliputi: $\mathrm{m}$. abdominalis, paraspinal, diafragma, dan otototot dasar panggul. Manfaat luas core stability telah disebut-sebut, dapat meningkatkan kinerja atletik, mencegah cedera dan untuk mengurangi nyeri punggung bawah (Richardson, Jull, Hodges, Hides, 1999).

Beberapa penelitian (Akuthota et.al, 2008; Desai, Marshall, 2010; Baerga-Varela, Abréu Ramos, 2006) menunjukkan bahwa latihan Core stabilitymerupakan komponen penting dalam rehabilitasi NPB. Panjabi (1992) mengusulkan sebuah modelterkenaldari sistemstabilitastulang belakang yangterdiri dari tigasubsistem: pasif subsistem(meliputi tulang, ligamendankapsul sendi), subsistemaktif(meliputi otot dan tendon), dansubsistemsaraf(terdiri dari sistem sarafpusat dansistem saraf perifer). Menurut model ini, ketigasubsistembekerja sama untukmemberikan stabilisasidengan mengontrolgerakantulang belakang. Dengan demikian, latihanCore stabilityyang efektifharus mempertimbangkankomponen motordansensoriklatihandanbagaimana mereka berhubungan dengansistem ini untukmeningkatkan stabilitastulang belakangyang optimal (Hodges PW, 2003). Selain itu,pelatihanCore stabilitymeliputilatihanterkait dengan pengaktifan utama otot-otot area tulang belakang danharus lebih ditingkatkan pada latihan statis yang kompleks, dinamis, dan fungsionalyangmelibatkankontraksiterkoordi nasiotot-otottulang belakang lokal dansuperfisial.

Corestability dapat digambarkan sebagai kotak berotot dengan perut di depan, paraspinals dan gluteals di belakang, diafragma sebagai atap, dan otot dasar panggul sebagai bagian bawah. Dalam kotak ini ada 29 pasang otot yang membantu untuk menstabilkan tulang belakang, panggul, dan rantai kinetik selama gerakan fungsional. Tanpa otot-otot ini tulang belakang akan menjadi tidak stabil secara mekanis dengan kekuatan tekanan sedikitnya $90 \mathrm{~N}$, beban 
tersebut jauh lebih kecil daripada berat tubuh bagian atas (Crisco, Panjabi, Yamamoto, Oxland, 1992). Ketika sistem bekerja sebagaimana mestinya, hasilnya adalah distribusi gaya yang tepat sehingga gaya maksimum, gaya translasi pada sendi dapat diminimalisir dengan adanya kekuatan otototot core (Fredericson, Moore, 2005).

Terdapat banyak bukti yang menunjukkan bahwa individu dengan NPB kronis dan nyeri sacroiliac diakibatkan oleh kelemahan otot-otot core (Hodges, 2003; Hides, Richardson, Jull, 1996; Hodges, Richardson, 1996; Newcomer, Jacobson, Gabriel, et.al, 2002; Hungerford, Gilleard, Hodges, 2003). Hodges (2003) pun membuktikan bahwa pasien NPB kronis mengalami peningkatan kelelahan, penurunan kekuatan otot dan infiltrasi lemak dari otot paraspinal. Bahkan banyak atlet tingkat tinggi menunjukkan tanda-tanda ketidakstabilan otot-otot core, dan hal ini yang dapat membuat mereka mengalami cedera muskuloskeletal (Leeton, 2004; Heidt, 1999). Atlet perempuan kemungkinan sangat rentan mengalami cedera ligamen cruciatumanterior jika kelemahan otot-otot core ditemukan (Leeton, 2004; Hewett, 2005). Selain itu, pasien NPB mengalami peningkatan kesulitan terhadap keseimbangan dan penurunan kemampuan untuk mengkompensasi gangguan tak terduga dari trunk. Pasien akan lebih banyak mengaktifkan otot besar superfisial sehingga kontrol dan aktivasi otototot bagian dalam spine terganggu. Ulasan sistemik juga telah sampai pada kesimpulan bahwa stabilisasi sangat membantu untuk gangguan spine, tetapi mungkin tidak superior terhadap latihan terapi lain (Liddle, 2004; Slade, 2006).

Dengan demikian, latihan core stability memiliki landasan teoritis yang lebih kuat untuk pencegahan gangguan muskuloskeletal khususnya pada NPB (Nyeri Pinggang Bawah) dibandingkan William's flexion.

\section{KESIMPULAN}

Berdasarkan hasil penelitian yang telah dilakukan, dapatlah disimpulkan bahwa Core stability (mean=4,56, $S D=1,130$ )lebih efektif dibandingkan dengan William's flexion $[$ mean $=2,78, \quad S D=0,972 ; \quad t(16)=-3,578$, $p=0,003$ ] dalam menurunkan nyeri pasien HNP. Hasil penelitian dengan One-Way ANOVA pun memperlihatkan bahwa terdapat perbedaan secara signifikan dalam penurunan nyeri yang dihasilkan oleh frekuensi treatment Core stability $[F(1,6)=12,333, p=0,007]$.

\section{DAFTAR PUSTAKA}

Akuthota V, Ferreiro A, Moore T, Fredericson M. 2008, Core Stability Exercise Principles, Curr Sports Med Rep, 7: 39-44.

American Academy of Orthopedic Surgeon. 2009, Low Back Pain [Online], updated May 2009, Available from: URL: http:// orthoinfo.aaos.org/topic.cfm?topic=A00311. 
Baerga-Varela L, Abréu Ramos AM. 2006, Core Strengthening Exercises for Low Back Pain. Bol Asoc Med P R, 98: 56-61.

Crisco JJ, Panjabi MM, Yamamoto I, Oxland TR. 1992, Stability of the Human Ligamentous Lumbar Spine, Part II: Experiment, Clin. Biomech, 7: 27-32.

Desai I, Marshall PW. 2010, Acute Effect of Labile Surfaces during Core Stability Exercises in People with and without Low Back Pain, J Electromyogr Kinesiol, 20: 1155-62.

Fredericson M, Moore T. 2005, Muscular Balance, Core Stability, and Injury Prevention for Middle-and Long-Distance Runners, Phys. Med. Rehabil. Clin. N. Am, 16:669-89.

Gilroy J. 2000, Basic Neurology, $3^{\text {rd }}$ ed, The Mcgraw-Hill Companies, United States of America.

Heidt RS. Jr, Sweeterman LM, Carlonas, RL. 1999, Avoidance of Soccer Injuries with Preseason Conditioning, Am. J. Sports Med, 27: 699-706.

Hewett TE, Myer GD, Ford KR. 2005, Reducing Knee and Anterior Cruciate Ligament Injuries among Female Athletes: A Systematic Review of Neuromuscular Training Interventions, J. Knee Surg, 18:82-8.

Hides JA, Richardson CA, Jull GA. 1996, Multifidusmuscle Recovery is not Automatic after Resolution of Acute, First-Episode Low Back Pain, Spine, 21:2763-9.

Hodges PW. 2003, Core Stability Exercise in Chronic Low Back Pain, Orthop Clin North Am, 34: $245-54$

Hodges PW, Richardson CA. 1996, Inefficient Muscular Stabilization of the Lumbarspine associated with Low Back Pain: A Motor Control Evaluation of Transversusabdominis, Spine, 21:2640-50.

Hungerford B, Gilleard W, Hodges P. 2003, Evidence of Altered Lumbopelvic Muscle Recruitment in the Presence of Sacroiliac Joint Pain, Spine, 28:1593-1600.

Khalid MU, Rafiq M, Zehra N. 2013, Effectiveness of William's Flexion Exercises in Management of Low Back Pain, Pakistan Journal of Medicine and Dentistry, Vol. 1 (01): 21-33.

Leeton DT, Ireland ML, Willson JD. 2004, Core Stability Measures as Risk Factors for Lower Extremity Injury in Athletes, Med. Sci. Sports Exerc, 36:926-34.

Liddle SD, Baxter GD, Gracey, JH. 2004, Exercise and Low Back Pain: What Works?, Pain, 107:176-90.

Lubis, I. 2003, Epidemiologi Nyeri Punggung Bawah dalam Nyeri Punggung Bawah, Kelompok Studi Nyeri PERDOSSI, 1-3.

Matsudaira K, Hara N, Arisaka M, Isomura T. 2011, Comparison of Physician's Advice for Nonspecific Acute Low Back Pain in Japanese Workers: Advice to Rest Versus Advice to Stay Active, Industrial Health, 49: 203-8.

Meliala L, Suryamiharja A, Purba JS, Anggraini H. 2000, Penuntun Praktis Penanganan Nyeri Neuropatik, Kelompok Studi Nyeri PERDOSSI, 1-3.

Newcomer KL, Jacobson TD, Gabriel DA, et al. 2002, Muscle Activation Patterns in Subjects with and without Low Back Pain, Arch. Phys. Med. Rehabil, 83:816-21. 
Olmaker K, Myers RR. 1998, Pathogenesis of Sciatic Pain: Role of Herniated Nucleus Pulposus and Deformation of Spinal Nerve Root and Dorsal Root Ganglion, 78-105.

Panjabi MM. 1992, The Stabilizing System of the Spine, Part II, Neutral Zone and Instability Hypothesis, J Spinal Disord, 5: 390-6.

Richardson C, Jull G, Hodges P, Hides J. 1999, Therapeutic Exercise for Spinal Segmental Stabilization in Low Back Pain: Scientific Basis and Clinical Approach, Churchill Livingstone, Edinburgh, NY.

Scheermesser M, Bachmann S, Schämann A, Oesch P, Kool J. 2012, A Qualitative Study on the Role of Cultural Background in Patients' Perspectives on Rehabilitation, BMC Musculoskelet Disord, $13 ; 5$.

Slade SC, Keating JL. 2006, Trunk-Strengthening Exercises for Chronic Low Back Pain: A Systematic Review, J. Manipulative Physiol. Ther, 29:163-73.

Strassels SA, Chen C, Carr DB. Postoperative analgesia: economics, resource use, and patient satisfaction in an urban teaching hospital. Anaesthesia and Analgesia.2002; 94: 130-7.

Wang X-Q, Zheng J-J, Yu Z-W, Bi X, Lou S-J, Liu J, et.al. 2012, A Meta-Analysis of Core Stability Exercise versus General Exercise for Chronic Low Back Pain, Report Information from ProQuest 28 July 2013 08:23. Publication info: PLoS One 7.12.

Weiss BD, ed. 1999, 20 Common problems in primary care. New York: McGraw-Hill, Health Professions Division. 